\title{
Precarious Parental Employment and Use of Alcohol or Substance during COVID-19
}

\author{
Jake Hart ${ }^{1}$, Wen-Jui Han ${ }^{*}$ \\ ${ }^{1}$ Mount Sinai Department of Psychiatry, New York University, New York, USA \\ ${ }^{2}$ Silver School of Social Work, New York University, New York, USA \\ Email: *wjh3@nyu.edu
}

How to cite this paper: Hart, J., \& Han, W.-J. (2021). Precarious Parental Employment and Use of Alcohol or Substance during COVID-19. Sociology Mind, 11, 33-51.

https://doi.org/10.4236/sm.2021.112004

Received: December 23, 2020

Accepted: April 5, 2021

Published: April 8, 2021

Copyright (c) 2021 by author(s) and Scientific Research Publishing Inc. This work is licensed under the Creative Commons Attribution International License (CC BY 4.0).

http://creativecommons.org/licenses/by/4.0/

(c) (i) Open Access

\begin{abstract}
As labor markets have become increasingly volatile, more workers are susceptible to conditions that threaten their economic security. COVID-19 has further laid bare such economic insecurity with far-reaching implications for coping skills and strategies. Using a cross-sectional dataset collected in May 2020 in the United States, we examined how precarious jobs were associated with alcohol or substance use among parents during the pandemic and if mental distress could explain such a link. Our multivariate regression analysis confirms that holding a job with precarious characteristics, such as feeling defenseless to authoritarian treatment at the workplace, was significantly associated with mental distress and doubled the probability of using alcohol or substance amid COVID-19. And mental distress might help explain such an association. Our analysis underscored the vulnerability faced by our workforce and how a public health crisis magnified the dire consequences of precarious employment on risky health behaviors.
\end{abstract}

\section{Keywords}

Alcohol or Substance Use, COVID-19, Mental Health, Pandemic, Precarious Parental Employment

\section{Introduction}

The combination of economic hardship, social isolation, and mental distress that has come to characterize the COVID-19 pandemic has significant implications for substance use during these unprecedented times. Overdose rates have been rising steadily since the beginning of the pandemic and have increased by $42 \%$ in May 2020 compared to rates from the same time last year, even with a record annual high of 71,000 overdose deaths in 2019 (Wan \& Long, 2020; Johnson, 
2020). An April poll showed that $16 \%$ of those surveyed reported an increase in alcohol use throughout the pandemic (Cramer, 2020). Many treatment centers have been forced to shut down or reduce services, while further isolation has paved the way for increased substance abuse (Goldberg, 2021). With only $\$ 425$ million of the federal government's $\$ 2$ trillion pandemic relief package going to mental health and substance abuse services, many experts believe that more must be done to avoid devastating consequences caused by substance abuse and mental distress (Ornstein et al., 2020).

The risk for substance abuse during COVID-19 is keen, in part, because once reliable coping strategies, like social support or physical exercise, have not been as feasible or regularly accessible due to social distancing measures and directives. As a result of the coronavirus pandemic, parents are stressed by work and family demands, making them especially vulnerable to maladaptive coping strategies like alcohol and substance use. While many may use alcohol or other substances to cope with stress or mental distress, alcohol or substance use has consistently proven to adversely affect mood, psychological functioning, and depressive symptoms (Schuckit, 1986). With economic uncertainty looming large for millions of families across the United States, stress has been widespread and abundant, and some may be more susceptible to economic instability and increased substance use than others.

We examined how jobs with precarious characteristics might be associated with increased alcohol and substance use among parents during the COVID-19 pandemic, and explored if mental distress might help explain such a link. We focused on parents because they are uniquely challenged during these trying times and are important to future generations and the functioning of the family unit. Furthermore, as the dilemmas between returning to childcare/school and instituting remote learning take center stage, parents are in especially precarious positions when it comes to effectively balancing the safety and educational and financial needs of their children and families. This paper thus highlights the far-reaching impact of job precarity on health and well-being through the lens of substance use, as the COVID-19 pandemic exposes the inequities experienced by precarious workers and the potential implications for future generations.

\subsection{Job Precarity}

Record rates of unemployment have rattled the economy and impacted millions of Americans across the country with dire consequences. As of June 2020, the unemployment rate was over $11 \%$ with almost 18 million people unemployed (Bureau of Labor Statistics, 2020). These numbers were down from the high of $15 \%$ in April, but significantly greater than the $4 \%$ before the pandemic (Bureau of Labor Statistics, 2020). The impact of the pandemic has hit hard for both low-wage low-skilled workers and the white-collar workforce (Pilkington \& Rao, 2020). Nonetheless, not only during the economic recession but also during this COVID-19 pandemic, workers who hold precarious jobs (e.g., low-wage, low-skill, 
and irregular work hours) have been hit the hardest (Pilkington \& Rao, 2020). Recent workplace trends have not helped but exacerbated the dire situation faced by many workers, particularly the vulnerable ones. In recent decades, labor markets have already been becoming more volatile and precarious, as evidenced by earnings, job benefits, work shifts and work hours (Kalleberg, 2011, 2018). With the growth of information technology and the service economy, the labor market has become polarized, leaving many uncertain of their job security, to great detriment of their well-being, and possibly substance using behavior (Benach et al., 2014; Kalleberg, 2018).

Although there is no all-encompassing definition of job precarity, experts emphasize the importance of using a multi-dimensional approach concerning both work conditions and relations, often linking it with nonstandard work hours (e.g., evenings, nights, weekends), unpredictability in schedules and hours, temporality of contracts, poor working conditions, and job insecurity (Kalleberg, 2011). For example, the Employment Precarious Scale was developed and tested in Europe and has been found to effectively identify the groups that are most vulnerable to precarious employment and how then precarious employment might be associated with workers' physical and mental health (Benach et al., 2016). Dimensions such as employment (in)stability, (low) material rewards, (erosion of) workers' rights and social protection, (de-standardized) working time arrangements, (dis)empowerment and (lack of) opportunities for employee representation, and (imbalanced) interpersonal power relations are all considered to be part of acute situations of employment precariousness (Vives et al., 2010). This paper thus followed large scholarship on documenting vulnerable groups (i.e., part-time, nonstandard work schedules, in service occupation) in the labor market (Kalleberg, 2011; Presser, 2003) and the work done by the group who established the EPRES scales (Vives et al., 2010) to be among the first in the United States to examine the association between job precarity and the increased use of alcohol or substance during the challenging times caused by the COVID-19 pandemic in the United States.

\subsection{Job Precarity, Pandemic Stress, and Coping Behaviors}

While the current pandemic has created widespread stress across the United States, those with precarious employment may be at an even greater risk, as precarious jobs have the potential to negatively impact an individual's mental health and physical well-being, with increases in anxiety, burnout, and psychological distress (Benach et al., 2014). Indeed, the Family Stress Model, born out of the Great Recession, asserts that economic hardship, by way of economic pressure, has the potential to generate significant parental psychological distress, which subsequently impacts the entire family unit (Conger et al., 2010). Those with precarious employment were more likely to be considered as essential workers during public health pandemic, such as workers in the service sector, and may be at a higher risk of contracting the virus at work, ultimately creating immense 
stress and anxiety. Furthermore, characteristics of job precarity, like inflexible and evening work hours, job insecurity, and a lack of autonomy, may increase the risk for work-family conflict and psychological distress, which can potentially further influence substance using behavior (Fan et al., 2019). Job precarity may also compromise self-esteem, relationships, and self-care (Benach et al., 2014), and can subsequently increase the likelihood of maladaptive coping strategies such as substance use (Glavin \& Young, 2017). Pandemic-induced isolation may also undermine typically used adaptive coping strategies, e.g., support groups, in favor of maladaptive coping behaviors like substance use (Hoffman, 2020). If not properly addressed, psychological distress can lead to increased substance use and produce a reciprocal relationship that further perpetuates distress (Newcomb et al, 1999).

Chronic stress, like one might experience in precarious employment, and stressful events, like that of concurrent public health and economic crises, may thus work as a compounding factor for potential substance use. The perceived job insecurity that is often associated with precarious employment is especially stressful because of the anticipatory nature and persistent uncertainty, which makes typical coping strategies less effective (Glavin \& Young, 2017). Job insecurity was significantly associated with substance use, possibly in part, because it serves as a work stressor that undermines a person's self-evaluation and self-image (Frone, 2008). Characteristics of job precarity like low skill and low autonomy have been shown to be associated with increased substance use (Wiesner et al., 2005).

Recent reports have noted that approximately one third of Americans now show signs of clinical anxiety and depression months into the pandemic, almost double the rates before COVID-19, with one in five Americans feeling a "major impact" on their health and well-being since the beginning of the pandemic (Fowers \& Wan, 2020). In a study on the effects of the COVID-19 pandemic on mental health and substance use in China, researchers found a significant increase in mental distress and hazardous and harmful alcohol use among those surveyed during quarantine (Ahmed et al., 2020). Moreover, a recent study showed that for each point increase of the unemployment rate, the opioid death rate would increase by $3.6 \%$ (Hollingsworth et al., 2017). Experts suggest that there could be anywhere between 27,000 and 154,000 deaths of despair (overdoses and suicides) as a result of COVID-19 related anguish and economic hardship, which at its highest estimate would be more than double the number of overdose deaths of the current annual record (Petterson et al., 2020). As a result of the pandemic, those who utilize support groups, like Alcoholics Anonymous, have been forced to replace lengthy daily group sessions with brief telephone calls at best or entire program abandonment at worst (Hoffman, 2020).

All in all, the concurrent public health and economic crises precipitated by the COVID-19 pandemic may have significant implications for substance using behavior. Parents holding precarious employment may be at a greater risk for in- 
creased alcohol and substance use, which has the potential to lead to negative life and health outcomes if not properly addressed. With the increase of anxiety, depression, and loneliness caused by the pandemic, many parents may attempt to reduce tension and assuage painful feelings by way of substance use, especially when considering the disruption of typical coping strategies and potential protective factors.

\section{Methods}

\subsection{Data}

We collected data via online Qualtrics in May 2020. The target sample was parents with at least one child aged 17 or younger and currently residing in the United States. With a target sample size of 1000 parents across the United States, recruitment was achieved through the researchers' networks (e.g., personal network, Facebook, online parenting support group) with convenience sampling due to constrained resources. This study was able to receive responses from every state in the United States including the District of Columbia. The share of participants from each state in our sample was qualitatively similar to the shares of the state population based on national statistics, with one exception that the home state of the researchers was oversampled ( $16 \%$ in our sample vs. $7 \%$ based on national statistics). Although participants were from all socioeconomic backgrounds, highly educated parents (e.g., graduate degree) might be overrepresented in comparison to the national average of educational achievement. This study was reviewed and approved by the authors' Institutional Review Board.

\subsection{Participants}

A sample of 1000 participants responded to the online survey. After excluding missing information, the final sample size for analysis was 933; details on missing cases are given below. Most of the participants were females, non-Hispanic White, and married. Approximately two-thirds of the participants had family income in the range of $\$ 50,000$ and $\$ 99,999$. Sixty percent of the participants were living in urban areas.

\subsection{Measures}

Increased use of alcohol/substance. We adopted an unpublished Pandemic Stress Index (Harkness et al., 2020) designed specifically to understand the related experience attributed to COVID-19 among vulnerable groups. Participants were asked to choose any experience they have encountered due to COVID-19 with a question of "Which of the following are you experiencing (or did you experience) during COVID-19 (coronavirus)?" We created a dichotomous variable with a value of 1 indicating if the respondents reported the increased use of alcohol or substance since COVID-19, and 0 otherwise.

Parental mental distress. This outcome was measured by the Kessler Psychological Distress Scale (Kessler et al., 2002) with 10 questions such as "I felt de- 
pressed" and "I felt hopeless" following a 5-point Likert scale $(1=$ none of the time to $5=$ all of the time). Participants were asked to answer these 10 questions in reference to the time since COVID-19. A summed score was calculated (range $=10$ to $50, \alpha=0.82$ ). A score of 20 to 24 was considered to be likely having a mild mental disorder, a score of 25 to 29 was considered to be likely having moderate mental disorder and a score of 30 and over was considered to be likely having a severe mental disorder.

Job precarity. This study utilized nine indicators to measure the degree of job precarity as one of the first attempt to do so in the United States. Three of the indicators were based on a consensus from established scholarship (Kalleberg, 2011; Presser, 2003) showing the most likely characteristics of a precarious job tend to be: part-time or overtime, low-skill (proxies by occupation), and a non-daytime schedule (or nonstandard work schedules). The remaining five indicators were adapted from an existing precarious employment scale, the Employment Precariousness Scale (EPRES), designed and validated by the Health Inequalities Research Group (GREDS-EMCONET) at Pompeu Fabra University in Spain (Vives et al., 2010; Vives et al., 2015). This scale tackles multidimensional aspects of job characteristics posing precarity to workers' economic security through work conditions and relations. These dimensions include employment (in) stability (e.g., permanent vs. temporary contract), disempowerment, vulnerability, low material rewards, and erosion of workers' rights and social protection (Vives et al., 2010). Below we provide details on each of these nine indicators.

For work hours, participants were asked about their usual weekly work hours before the COVID-19 pandemic. Responses ranged from "less than 10 hours", "10 - 20 hours", "21 - 34 hours", “35 - 44 hours", “45 - 54 hours” or " $55+$ hours". To avoid small cell sizes, respondents who answered weekly work hours less than 35 hours were categorized as "part-time" those who answered working 35 44 hours as "full-time" and those who answered working 45 or more hours per week as "over time."

To proxy for low-skill, we used the information on occupation. The participants were asked about their occupation before the COVID-19 pandemic. Ten occupation categories were provided in the survey following the U.S. Census survey (i.e., Current Population Survey): professional and related occupations; service occupations; sales and related occupations; office and administrative support occupations; farming, fishing, and forestry occupations; construction and extraction occupations; installation, maintenance, and repair occupations; production occupations; transportation and material moving occupations; or Armed Forces. Three dichotomous variables were created representing professional or managerial occupation, service/sale/office support occupation, and all other occupations (no respondent answered to be in Armed Forces). In this study, compared to professional or managerial occupations, occupations including services/sales/offices and all others were considered to be more likely to 
be low-skill.

For a nonstandard work schedule, participants were asked about their usual work schedule before the COVID-19 pandemic. Choices were provided as follows: "Daytime (anytime between 6 a.m. and 6 p.m.)", "Evening (anytime between 2 p.m. and 9 p.m.)", "Nights (anytime between 9 p.m. and 8 a.m.)", "Rotating shift (changes periodically from day to evenings or nights)", "Split shift (consisting of two distinct periods each day)", or "Irregular hours." Most respondents answered working daytime hours, and thus a dichotomous variable was created to indicate if the participants reported working during any non-daytime hours.

For employment instability that is part of EPRES, participants were asked about the duration of the contract status for their current/most recent job. Choices ranged from 0 (permanent contract) to 4 (less than 6 months). This variable was treated as continuous with higher score representing more unstable (or temporary) employment.

We measured the disempowerment as part of EPRES with three questions asking about the level of negotiation of employment conditions related to workplace schedule, weekly work hours, and wages or salaries. Three choices were provided with 1 (by the union or collective agreement), 2 (by both the employer and employee) or 3 (by the employer). An average score was created from these three items with a higher score representing more disempowerment. This scale has excellent reliability $(\alpha=0.82)$.

We measured vulnerability as part of EPRES with six questions asking about if the participants felt defenseless to authoritarian treatment at the workplace. Questions include such as "feel afraid to demand better working conditions", "feel defenseless towards unfair treatment by your superiors", with responses ranging from 0 (never) to 4 (always). An average score was calculated from these six items with the higher the score the more vulnerable the employee was $(\alpha=0.83)$.

We measured low material reward as part of EPRES with two questions asking if the wages or salaries were enough to cover basic needs and to cover unexpected expenses. Responses range from 0 (very much) to 4 (not at all). An average score was calculated from these two items with higher score representing lower material reward (and thus potentially economic deprivation) $(\alpha=0.81)$.

We measured rights as part of EPRES by asking participants to select the benefits they were entitled to at the workplace. Seven benefits were asked, including paid vacation, pension, severance pay, maternity/paternity leave, time off due to family or personal reasons, weekly/monthly/annual holidays, and unemployment compensation. A summed score ranging from 0 to 7 was calculated and then reversed so that the higher the score, the fewer rights the employee was entitled to.

To measure exercise rights as part of EPRES, five rights were asked of participants to see if they could exercise at the workplace without obstacles. Each of these five questions used a 5-Likert scale from 0 (always) to 4 (never). These five rights were weekly/monthly/annual holiday breaks, sick leave, go to the doctor, 
take a vacation, and request a day off for family or personal reasons. An average score was calculated from these five items so that higher scores represent more obstacles to exercise workplace rights $(\alpha=0.88)$.

Sociodemographic characteristics. We included in our analyses an extensive set of sociodemographic characteristics that have been shown in prior research to be associated with parental work and their economic prospect (e.g., Kalleberg, 2011). Such an inclusion allowed us to partially address selection and omitted-variable biases. We included the following parental characteristics: gender (male vs. female), age (less than 35 years old, 35 - 44 years as the reference group, or 45 or older), education (less than a college degree, college degree as the reference group, or graduate degree), race-ethnicity (non-Hispanic White as the reference group, non-Hispanic Black, Hispanic, of all other groups), and marital status (not-married vs. otherwise). We included the following family characteristics: number of children aged 0 - 5, number of children aged $6-17$, number of family members living together, family income (less than $\$ 50,000, \$ 50,000$ $\$ 69,000, \$ 70,000$ - $\$ 99,999$ as the reference group, or $\$ 100,000$ or more), subjective social status, location (suburban, rural, vs. urban), and region (Midwest, South, and West, vs. Northeast). Subjective social status was measured using the MacArthur Scale of Subjective Social Status, asking participants to rank themselves in reference to the nation on a ladder ranging from 1 - 10 (Adler et al., 2000).

\subsection{Empirical Strategy}

Most of the variables had less than $2 \%$ of missing data, except variables related to job precarity that contained about $4 \%$ missing data (i.e., disempowerment, exercise rights). When the missing rate is less than $5 \%$, analyses of complete cases may not lead to a great deal of bias (Allison, 2000). The final analyzed samples were 933. Missing data analysis indicates that those excluded from the analysis (i.e., missing predictor variables) were more likely to be female, in the age group of 45 or older, single parent, having more family members living together, having income in the category of $\$ 50,000$ or less, working part-time, more likely to hold nonstandard work schedules, and more likely to hold jobs with precarious characteristics related to the temporary contract and low material rewards. These differences were at least at $5 \%$ significance level. These differences suggest that our estimates were more likely to underestimate the association between job precarity and increased use of alcohol or substance.

Multivariate regression analysis was used with a logistic regression for a dichotomous outcome with Huber-White standard errors that are robust to unspecified heteroskedasticity (Greene, 2012). All analyses control for sociodemographic characteristics as detailed in Measures section. We first estimated a model (Model 1) considering job precarity and all sociodemographic characteristics. We then calculated predicted probabilities based on this logistic regression results so that the estimates are easier to interpret than odds ratio. Several 
scenarios were simulated by manipulating the characteristics related to job precarity that achieved statistical significance. These scenarios demonstrate whether the likelihood of increased use of alcohol or substance would increase or decrease depending on the presence (or absence) of a precarious job characteristic. Lastly, we estimated a second model (Model 2), same as Model 1, but add control for parental mental distress. These two models allowed us to explore if mental distress help explain some of the links between job precarity and the use of alcohol or substance.

\section{Results}

\subsection{Descriptive Picture}

Table 1 shows the descriptive statistics for all analyzed variables in this study. About $21 \%$ of the sampled participants reported they have increased the use of alcohol or substance due to COVID-19. Regarding characteristics related to job precarity, the majority of parents reported working full-time (35 - 44 hours), only $10 \%$ reported working at nonstandard schedules, and over half of the parents reported to have a professional/managerial occupation with another third working at occupations related to services, sales, or office jobs. Almost $90 \%$ of the respondents worked at jobs with longer-term (i.e., one year or more) or permanent contract. Whereas respondents reported to feel disempowered $(\mathrm{M}=$ $2.30, \mathrm{SD}=0.65$ on a scale of $1-3$ ), the average ratings for other aspects of EPRES scales related to vulnerability, material reward, rights, and exercising rights were about below average (below 2.0 on a scale of 0 - 4). Finally, the average score of mental distress was just above 25 , a cutoff score point considered likely to have moderate mental distress (Kessler et al., 2002).

The demographic characteristics of this sample indicate that most of these participants were married mothers younger than the ages of 45. And, about two-thirds of the participants were non-Hispanic White, with another $20 \%$ and $10 \%$ of the participants being non-Hispanic Black and Hispanic, respectively. Surveyed parents had about on average one child of each within the age range of 0 - 5 and of $6-17$, and the average number of family members living together was almost four. About two-thirds of the participants had a college degree or higher educational achievement. Most of the samples had family income in the range of $\$ 50,000$ and $\$ 99,999$, and the average subjective social status was slightly higher than five on a 1-10 scale. Lastly, most of the samples lived in the urban areas, and the share of the sample by region was about equally distributed with a slightly greater share of the participants from the South region. These demographic characteristics point to the direction that the sample might be more advantaged, relatively speaking, than the national averages on several socioeconomic indicators.

\subsection{Correlation between Focal Variables}

Table 2 presents correlation coefficients between focal variables-precarious 
Table 1. Descriptive statistics on analyzed variables $(\mathrm{N}=933)$.

\begin{tabular}{|c|c|}
\hline Variables & $\% /$ Mean (SD) \\
\hline Male (\%) & 43.77 \\
\hline \multicolumn{2}{|l|}{ Age $(\%)$} \\
\hline $18-34$ & 32.73 \\
\hline $35-44$ & 48.69 \\
\hline $45+$ & 18.57 \\
\hline \multicolumn{2}{|l|}{ Education (\%) } \\
\hline Less than college & 36.18 \\
\hline College degree & 48.64 \\
\hline Graduate degree & 15.18 \\
\hline \multicolumn{2}{|l|}{ Race-Ethnicity (\%) } \\
\hline Non-Hispanic White & 63.61 \\
\hline Non-Hispanic Black & 20.67 \\
\hline Hispanic & 10.28 \\
\hline All others & 5.44 \\
\hline Not married (\%) & 4.59 \\
\hline Number of living together & $3.50(0.88)$ \\
\hline Number of kids aged $0-5(>0)$ & $1.16(0.45)$ \\
\hline Number of kids aged 6 - $17(>0)$ & $1.26(0.64)$ \\
\hline \multicolumn{2}{|l|}{ Income (\%) } \\
\hline Less than $\$ 50,000$ & 19.32 \\
\hline$\$ 50,000-\$ 69,999$ & 31.29 \\
\hline$\$ 70,000-\$ 99,999$ & 34.91 \\
\hline$\$ 100,000+$ & 14.49 \\
\hline Subjective social status & $5.74(1.63)$ \\
\hline \multicolumn{2}{|l|}{ Location (\%) } \\
\hline Urban & 60.27 \\
\hline Suburban & 30.54 \\
\hline Rural & 9.19 \\
\hline \multicolumn{2}{|l|}{ Region (\%) } \\
\hline Northwest & 26.22 \\
\hline Midwest & 16.35 \\
\hline South & 35.89 \\
\hline West & 21.54 \\
\hline \multicolumn{2}{|l|}{ Job Precarity } \\
\hline \multicolumn{2}{|l|}{ Weekly work hours before COVID-19 (\%) } \\
\hline Less than 35 hours & 12.65 \\
\hline 35 - 44 hours & 74.80 \\
\hline $45+$ hours & 12.55 \\
\hline Nonstandard work schedule before COVID-19 (\%) & 9.57 \\
\hline
\end{tabular}




\section{Continued}

\begin{tabular}{cc}
\hline Occupation (\%) & \\
Professional/Manager & 53.54 \\
Service/Sale/Clerical & 37.79 \\
All others & 8.67 \\
EPRES-Employment instability, type of contract (\%) & \\
$\quad$ Permanent (0) & 25.23 \\
One year or more (1) & 62.92 \\
Temporary, non-fixed term (2) & 4.86 \\
Temporary, 6 - 12 months (3) & 5.07 \\
Temporary, less than 6 month (4) & 1.93 \\
EPRES - Disempowerment (1 - 3) & $2.30(0.65)$ \\
EPRES - Vulnerability (0 - 4) & $1.19(0.77)$ \\
EPRES - Material reward (0 - 4) & $1.76(0.90)$ \\
EPRES - Rights (0 - 4) & $1.92(1.38)$ \\
EPRES - Exercise Rights (0 - 4) & $1.80(0.93)$ \\
Parental mental health since COVID - 19 (10 - 50) & $24.70(6.40)$ \\
Outcome: Increased alcohol or substance use (\%) & 20.84
\end{tabular}

Table 2. Correlations between job precarity and increased use of alcohol/substance.

\begin{tabular}{|c|c|c|c|c|c|c|c|c|c|c|}
\hline & 1 & 2 & 3 & 4 & 5 & 6 & 7 & 8 & 9 & 10 \\
\hline 1. Weekly wk hrs before COVID-19 & - & & & & & & & & & \\
\hline $\begin{array}{l}\text { 2. Nonstandard schedule before } \\
\text { COVID-19 }\end{array}$ & -0.015 & - & & & & & & & & \\
\hline 3. Occupation & 0.027 & $0.149^{* * *}$ & - & & & & & & & \\
\hline 4. EPRES-Employment instability & -0.033 & $0.119^{* * *}$ & $0.169^{* * *}$ & - & & & & & & \\
\hline 5. EPRES-Disempowerment & -0.006 & -0.015 & 0.018 & 0.045 & - & & & & & \\
\hline 6. EPRES-Vulnerability & 0.003 & $-0.098^{* *}$ & $0.098^{* *}$ & -0.020 & $-0.091^{\star *}$ & - & & & & \\
\hline 7. EPRES-Material reward & $-0.134^{* * *}$ & $0.192^{\star * *}$ & $0.254^{* * *}$ & $0.329^{* * *}$ & $0.078^{*}$ & $-0.072^{\star}$ & - & & & \\
\hline 8. EPRES-Rights & 0.059 & $0.099^{* * *}$ & 0.000 & $0.331^{* * *}$ & $0.186^{* * *}$ & $-0.333^{* * *}$ & $0.271^{\star * *}$ & - & & \\
\hline 9. EPRES-Exercise Right & 0.017 & 0.018 & -0.034 & $0.287^{\star * *}$ & $0.152^{* * *}$ & -0.021 & $0.177^{\star * *}$ & $0.376^{\star \star *}$ & - & \\
\hline 10. Mental distress & 0.015 & $-0.107^{\star \star \star}$ & $0.109^{* * *}$ & $0.079^{\star}$ & -0.017 & $0.522^{\star * \star}$ & $0.086^{* *}$ & $-0.081^{\star}$ & $0.138^{\star * *}$ & - \\
\hline 11. Increased alcohol or substance use & 0.051 & -0.042 & 0.048 & -0.042 & -0.062 & $0.105^{\star * *}$ & $0.068^{*}$ & -0.052 & -0.026 & $0.194^{\star * *}$ \\
\hline
\end{tabular}

Note. ${ }^{\star} p<0.05 .{ }^{* *} p<0.01 .{ }^{* * *} p<0.001$.

job characteristics, mental distress, and increased alcohol or substance use. In general, most of the precarious job characteristics, as expected, were strongly correlated with each other. Increased alcohol or substance use was strongly positively correlated with ESPRES-vulnerability and material reward as well as parental mental distress.

Correlations between variables are helpful in gauging the degree of the inde- 
pendent variables predicting the dependent variable, information on correlation is also helpful in gauging the possibility for multicollinearity. Multicollinearity is a condition when highly correlated variables are included in the same multivariate regression models that could produce unstable coefficient estimates and highly inflated standard errors (Chatterjee et al., 2000). Information in Table 2 does not suggest multicollinearity. In addition, we used variance inflation factor (VIF) after estimating our multivariate regression model, indicating no issue of multicollinearity. Variables whose VIF values are greater than 10 are worth further investigation, all the variables in our analysis had VIF values equal to or smaller than 2 (Chatterjee et al., 2000).

\subsection{Associations between Job Precarity, Mental Distress, and Alcohol or Substance Use}

Table 3 presents coefficient estimates from two logistic regression models on the likelihood of increased use of alcohol or substance due to COVID-19 with model 1 considering all sociodemographic characteristics detailed in Measures section and model 2, same as model 1, but adds control for mental distress. Whereas most of precarious job characteristics were not significantly associated with the likelihood of increased use of alcohol or substance, results indicate that working 45 or more hours per week (vs. working 35 - 44 hours), feeling vulnerable at workplace, having less than a college degree (vs. college degree), and more people living together were significantly positively associated with the likelihood of increased use of alcohol or substance. In contrast, being older (45+ vs. 35 - 44) and having more children aged 0 - 5 were significantly negatively associated with the likelihood of increased use of alcohol or substance due to COVID-19.

For easy interpretation of logistic regression estimates, we calculated the predicted average probabilities of increased use of alcohol or substance due to COVID-19, which was about 0.21 after considering all variables shown in Table 3. The probabilities would then increase from 0.19 to 0.33 if a parent changed their working hours from working less than 45 hours per week to working 45 or more hours per week, almost doubling the probability of increased use of alcohol or substance due to COVID-19. In addition, the predicted probabilities of increased use of alcohol or substance due to COVID-19 would increase from 0.14 to 0.38 if the respondent reported no vulnerability at the workplace to the highest level of vulnerability. Even with one degree of increase from 0 to 1 on a scale of 4 for the vulnerability would increase the probabilities from 0.14 to 0.19 , over one-third of increase in the likelihood of using alcohol of substance, and an average level of vulnerability (a score of 2 on a scale of $0-4$ ) would increase the probabilities from 0.14 to 0.24 , almost doubling the probabilities of increased use of alcohol or substance due to COVID-19.

Lastly, model 2 presents logistic regression coefficient estimates adding control for mental distress. Results indicate that vulnerability at workplace was no longer statistical significance and the magnitude of the estimates for almost all 
Table 3. Multivariate regression estimates of job precarity on Increased use of alcohol/substance.

\begin{tabular}{|c|c|c|}
\hline & Model 1 & Model 2 \\
\hline \multicolumn{3}{|l|}{ Weekly work hours before COVID-19 (Ref: 35 - 44 hours) } \\
\hline Less than 35 hours & $0.364(0.324)$ & $0.351(0.334)$ \\
\hline $45+$ hours & $0.998(0.296)^{* * *}$ & $0.993(0.295)^{* * *}$ \\
\hline Nonstandard work schedule before COVID-19 & $-0.467(0.404)$ & $-0.440(0.406)$ \\
\hline \multicolumn{3}{|l|}{ Occupation (Ref: Professional/Manager) } \\
\hline Service/Sale/Clerical & $-0.143(0.232)$ & $-0.133(0.230)$ \\
\hline All others & $-0.203(0.134)$ & $-0.087(0.364)$ \\
\hline EPRES-Employment instability & $-0.203(0.134)$ & $-0.181(0.136)$ \\
\hline EPRES-Disempowerment & $-0.276(0.143)$ & $-0.253(0.144)$ \\
\hline EPRES-Vulnerability & $0.363(0.152)^{*}$ & $0.154(0.173)$ \\
\hline EPRES-Material reward & $0.117(0.131)$ & $0.115(0.126)$ \\
\hline EPRES-Rights & $-0.092(0.083)$ & $-0.093(0.085)$ \\
\hline EPRES-Exercise Rights & $0.105(0.129)$ & $0.087(0.129)$ \\
\hline Parental mental distress & & $0.062(0.017)^{* * *}$ \\
\hline Parental gender: Male & $-0.097(0.190)$ & $-0.128(0.192)$ \\
\hline \multicolumn{3}{|l|}{ Age (Ref: 35 - 44) } \\
\hline $18-34$ & $-0.056(0.225)$ & $-0.049(0.225)$ \\
\hline $45+$ & $-0.634(0.264)^{\star}$ & $-0.672(0.270)^{\star}$ \\
\hline \multicolumn{3}{|l|}{ Education (Ref: College degree) } \\
\hline Less than college & $0.384(0.195)^{\star}$ & $0.338(0.197)$ \\
\hline Graduate degree & $0.283(0.329)$ & $0.416(0.333)$ \\
\hline \multicolumn{3}{|l|}{ Race-Ethnicity (Ref: Non-Hispanic White) } \\
\hline Non-Hispanic Black & $-0.105(0.234)$ & $-0.077(0.235)$ \\
\hline Hispanic & $0.541(0.325)$ & $0.530(0.311)$ \\
\hline All others & $-0.858(0.546)$ & $-0.704(0.539)$ \\
\hline Not married & $-0.167(0.546)$ & $-0.163(0.547)$ \\
\hline Number of living together & $0.354(0.136)^{\star \star}$ & $0.340(0.135)^{*}$ \\
\hline Number of kids aged 0 - 5 & $-0.374(0.196)^{*}$ & $-0.356(0.194)$ \\
\hline Number of kids aged 6 - 17 & $0.109(0.146)$ & $0.115(0.145)$ \\
\hline \multicolumn{3}{|l|}{ Income (Ref: $\$ 70,000$ - $\$ 99,999)$} \\
\hline Less than $\$ 50,000$ & $-0.470(0.301)$ & $-0.412(0.301)$ \\
\hline$\$ 50,000-\$ 69,999$ & $0.183(0.213)$ & $0.191(0.217)$ \\
\hline$\$ 100,000+$ & $-0.090(0.374)$ & $-0.175(0.368)$ \\
\hline Subjective social status & $-0.061(0.067)$ & $-0.048(0.069)$ \\
\hline \multicolumn{3}{|l|}{ Location (Ref: Urban) } \\
\hline Suburban & $0.199(0.223)$ & $0.149(0.222)$ \\
\hline Rural & $0.225(0.318)$ & $0.150(0.323)$ \\
\hline
\end{tabular}




$\begin{array}{ccc}\text { Region (Ref: Northeast) } & & \\ \text { Midwest } & -0.418(0.303) & -0.548(0.304) \\ \text { South } & 0.070(0.230) & -0.022(0.235) \\ \text { West } & 0.026(0.253) & -0.124(0.255) \\ \text { Pseudo R-Square } & 0.119 & 0.130 \\ \text { N } & 933 & 933\end{array}$

Note. Numbers represent coefficients with robust standard errors in parenthesis. ${ }^{\star} p<0.05 .{ }^{* *} p<0.01 .{ }^{* * *} p<0.001$.

of the precarious employment characteristics became smaller. Parental mental distress was significantly associated with higher likelihood of increasing use of alcohol or substance. Such a result suggests that mental distress might help explain the links between job precarity and the use of alcohol or substance.

\section{Discussion and Conclusion}

We examined whether job precarity might be associated with increased alcohol and substance use during the COVID-19 pandemic, and explored if mental distress might help explain such a link. Our results partially confirm the connection, as vulnerability and working overtime, key characteristics of job precarity, were associated with increased substance use, and mental distress helped explained such a link. These results have significant implications for the concurrent public health and economic crises currently facing the United States. Our results also shed light on how people in vulnerable positions might be at risk of using alcohol or substance. We highlighted a few such results below.

The positive association between vulnerability, or feeling defenseless to authoritarian treatment at the workplace, and increased substance use underscores the added risks of job precarity during the COVID-19 pandemic for families with children across the country. Feeling vulnerable at work may make it more difficult to insist on protections and precautions against the pandemic, such as taking sick leave, and can ultimately lead to maladaptive coping strategies like substance use. Such feelings of powerlessness and vulnerability may also reduce perceptions of self-efficacy, which can potentially cause parents to rely on alcohol and substance to regulate their self-esteem (Frone, 1999). Feeling defenseless against authoritarian treatment can also generate feelings of incompetence and despondency (Benach et al., 2014), potentially increasing anxiety and depression and negatively impacting mental health to the point that many turn to substance use in order to self-medicate, regulate negative emotions, and reduce the tension they experience as a result of workplace stress. Our result related to working overtime and parental mental distress speaks to the stress associated with job precarity. Increased substance use has the potential to then induce more psychological distress for parents (Schuckit, 1986).

Furthermore, previous research focusing on psychosocial qualities of the work environment to understand the association between work stress and substance 
use has suggested that limited job control and input into decision making, along with interpersonal conflict with supervisors and heavy workload, has the potential to increase substance use by way of alienating individuals (Frone, 1999). This literature may help explain how vulnerability at the workplace could be such a risk factor. This line of research has also suggested that both work stress and substance use have the potential to spill over into family dynamics, interfere with social roles, impact family relationships, create interpersonal conflict, and ultimately increase the risk for further substance use (Frone, 1999). A dire consequence of the increase in the use of alcohol or substance among parents is directly related to how they interact with children; parents using substances are more likely to exert punitive parenting, and in the worst case, substance abuse increases the risk for child maltreatment and domestic violence (Gruber \& Taylor, 2006). Our results related to vulnerability at work may thus suggest that whereas practitioners, including social workers, are equipped with the best knowledge to address alcohol and substance use issues, advocacy for those who feel defenseless at the workplace may be an important component of effectively addressing the increased prevalence of alcohol or substance use among parents with children. Moreover, social workers, among others, have the potential to bolster effective communication within organizations. Improvements in communication throughout an organization can create opportunities for empowerment among vulnerable workers, build trust across the workplace hierarchy, and support leadership in satisfying their goals and expectations.

Likewise, our results indicating parents with lower levels of education were more likely to increase the use of alcohol or substance, further echo the significance associated with vulnerability at workplace. Those with low levels of education are also the ones likely to hold precarious jobs as shown in previous research (Kalleberg, 2011), and may have fewer resources that put them at greater risk of contracting the virus, ultimately leading to an increase in stress and substance use. Indeed, the COVID-19 pandemic has disrupted normal routines and further perpetuated many of the pre-existing social inequities to make life more difficult for millions of families across the country (Pilkington \& Rao, 2020).

Our result also indicates that a greater number of people living together was associated with more substance use. Previous studies have found that more people living together, particularly in a crowded space, has the potential to increase stress and lead to substance use based on its reciprocal nature with distress (Newcomb et al., 1999). Many families are forced to quarantine under one roof as a result of the current public health crisis, and unfortunately, these also tend to be families with the least resources to cope with economic and psychological stress (Hubler et al., 2020). With more people living together, there may be a greater risk for contracting the virus and added concern for each member within the household, ultimately leading to more distress and substance use. Numerous reports have documented how entire families have been infected by the virus due to small or crowded living spaces (Hubler et al., 2020). 
The pandemic has laid bare and even worsened the inequalities that have long existed in the United States. Our results confirm that parents who were likely to be in a vulnerable position, and thus suffered from inequalities, were also more likely to increase maladaptive behaviors such as using alcohol or substances. Our results thus point to the direction that practitioners, like social workers, hold a critical key to utilizing a person-in-environment approach with both micro- and macro-perspectives when attending to the needs of the entire family. A systems approach would also support the complex dynamics at play for those affected by increased substance use and potential psychological distress because of the pandemic.

\subsection{Limitations}

We note several limitations with the intention to strengthen future studies. The first is that we utilized a cross-sectional research design, and thus we could only assert association rather than causality. Further, due to resource constraints, we adopted non-representative convenience sampling that casts limitation to our understanding of the full scale of the impacts due to COVID-19 related experiences. Similarly, our sample tended to be from a relatively advantaged sociodemographic background and thus the associations detected here may likely underestimate the true associations between precarious employment and increased use of alcohol or substance induced by COVID-19. Another key limitation is that our measures did not specify the amounts of alcohol or substances used by parents, and we were therefore unable to determine the difference between mere use and more problematic abuse. Further research that includes more information on the specificities of substance use, like types of substances or time of use, would be valuable in devising informed policies and programs. Furthermore, the measures were self-reported and may have been subjected to the social desirability effect (Edwards, 1957). If there was truly a social desirability effect, our result would only underestimate the association between job precarity and the likelihood of using alcohol of substance as participants tend to under-report the use of alcohol or substance. Lastly, we could only claim to explore if parental mental distress may help explain the link between job precarity and alcohol or substance use only because our data did not allow for proper temporal sequence between these three sets of variables. To properly examine such a pathway, we would need to observe parental precarious employment at time 1, parental mental distress at time 2, and then use of alcohol or substance at time 3. We note that job precarity was asked in reference to timeframe before COVID-19 and mental distress and use of alcohol or substance were asked in reference to timeframe after COVID-19. Future research is warranted to collect data with proper temporal sequence to properly examine such a pathway.

\subsection{Conclusion}

Our results on the associations between job precarity and increased alcohol and 
substance use during the COVID-19 pandemic have significant implications for the health and well-being of parents and families across the United States. Precarious employment does not help, and indeed may worsen the use of alcohol or substance as many are confronting the bleak economic landscape. The inaccessibility of once-reliable coping strategies has further heightened the risk of alcohol or substance use. The potential lasting consequences can possibly even extend across generations if not enough is done to address those most affected by the dual public health and economic crises currently underway.

Practitioners including social workers play a critical role in supporting parents at risk of increased substance use and those most vulnerable in the pandemic, as some are at greater risk than others. However, given the challenges posed by current public health and economic crises, along with how thousands of parents and families across the United States might have suffered from these crises in terms of their bleak economic prospects and vulnerability to maladaptive behaviors, practitioners including social workers may need to recognize, rethink, and reevaluate our assumptions in the type of care we are providing to better the well-being of parents. Practitioners and social service organizations can better protect the most vulnerable by first recognizing potential risk factors and preemptively intervening with support measures before an increase in substance use transpires. A more systematic approach with both micro- and macro- perspectives perhaps is required for a deeper understanding of the root causes of issues faced by parents during this pandemic. By doing so, we can then truly serve families and communities in building a resiliency that has the potential to not only support parents during this current crisis but also reveal the strength they possess to overcome possible future adversities.

\section{Acknowledgements}

The authors would like to express our appreciation to the parents who generously and graciously shared their precious time with us to participate in this survey. This study was supported by an internal funding from the NYU Silver School of Social Work.

\section{Conflicts of Interest}

The authors declare no conflicts of interest regarding the publication of this paper.

\section{References}

Adler, N. E., Epel, E. S., Castellazzo, G., \& Ickovics, J. R. (2000). Relationship of Subjective and Objective Social Status with Psychological and Physiological Functioning: Preliminary Data in Healthy White Women. Health Psychology, 19, 586-592.

Ahmed, M. Z., Ahmed, O., Aibao, Z., Hanbin, S., Siyu, L., \& Ahmad, A. (2020). Epidemic of COVID-19 in China and Associated Psychological Problems. Asian Journal of Psychiatry, 51, 102092. https://doi.org/10.1016/j.ajp.2020.102092

Allison, P. D. (2000). Missing data. Thousands Oaks, CA: Sage publishing. 
Benach, J., Vives, A., Amable, M., Vanroelen, C., Tarafa, G., \& Muntaner, C. (2014). Precarious Employment: Understanding an Emerging Social Determinant of Health. Annual Review of Public Health, 35, 229-253.

https://doi.org/10.1146/annurev-publhealth-032013-182500

Chatterjee, S., Hadi, A. S., \& Price, B. (2000). Regression Analysis by Example (3rd ed.). Hoboken, NJ: John Wiley and Sons.

Conger, R. D., Conger, K. J., \& Martin, M. J. (2010). Socioeconomic Status, Family Processes, and Individual Development. Journal of Marriage and Family, 72, 685-704. https://doi.org/10.1111/j.1741-3737.2010.00725.x

Cramer, M. (2020). Could all Those "Quarantinis" Lead to Drinking Problems? The New York Times.

https://www.nytimes.com/2020/05/26/health/coronavirus-alcohol-addiction.html

Edwards, A. (1957). The Social Desirability Variable in Personality Assessment and Research. New York: The Dryden Press.

Fan, W., Lam, J., \& Moen, P. (2019). Stress Proliferation? Precarity and Work-Family Conflict at the Intersection of Gender and Household Income. Journal of Family Issues, 40, 2751-2773. https://doi.org/10.1177/0192513X19862847

Fowers, A., \& Wan, W. (2020). A Third of Americans Now Show Signs of Clinical Anxiety or Depression, Census Bureau Finds Amid Coronavirus Pandemic. The Washington Post.

https://www.washingtonpost.com/health/2020/05/26/americans-with-depression-anxie ty-pandemic/

Frone, M. R. (1999). Work Stress and Alcohol Use. Alcohol Research \& Health, 23, 284-291.

Frone, M. R. (2008). Are Work Stressors Related to Employee Substance Use? The Importance of Temporal Context Assessments of Alcohol and Illicit Drug Use. Journal of Applied Psychology, 93, 199-206. https://doi.org/10.1037/0021-9010.93.1.199

Glavin, P., \& Young, M. (2017). Insecure People in Insecure Places: The Influence of Regional Unemployment on Workers' Reactions to the Threat of Job Loss. Journal of Health and Social Behavior, 58, 232-251. https://doi.org/10.1177/0022146517696148

Goldberg, E. (2021). "Relapsing Left and Right": Trying to Overcome Addiction in a Pandemic. The New York Times.

https://www.nytimes.com/2021/01/04/nyregion/addiction-treatment-coronavirus-newyork-new-jersey.html

Greene, W. H. (2012). Econometric Analysis (7th ed.). Boston, MA: Pearson Education.

Gruber, K. J., \& Taylor, M. F. (2006). A Family Perspective for Substance Abuse: Implications from the Literature. Journal of Social Work Practice in the Addictions, 6, 1-29. https://doi.org/10.1300/J160v06n01_01

Harkness, A., Behar-Zusman, V. \& Safren, S. A. (2020). Understanding the Impact of COVID-19 on Latino Sexual Minority Men in a US HIV Hot Spot. AIDS and Behavior, 24, 2017-2023. https://doi.org/10.1007/s10461-020-02862-w

Hoffman, J. (2020). Online Help to Stay Sober during a Pandemic. The New York Times. https://www.nytimes.com/2020/03/26/health/coronavirus-sobriety-online-help.html

Hollingsworth, A., Ruhm, C., \& Simon, K. (2017). Macroeconomic Conditions and Opioid Abuse. NBER Working Paper 23192. https://www.nber.org/papers/w23192.pdf https://doi.org/10.3386/w23192

Hubler, S., Fuller, T., Singhvi, A., \& Love, J. (2020). Many Latinos Couldn't Stay Home. Now Virus Cases Are Soaring in Their Communities. The New York Times. 
https://www.nytimes.com/2020/06/26/us/corona-virus-latinos.html

Johnson, C. K. (2020). New Peak of 71K US Overdose Deaths in 2019 Dashes Hopes. The Associated Press News. https://apnews.com/dc15cae6e299bbbf73ce0e4b67d4d02d

Kalleberg, A. L. (2011). Good Jobs, Bad Jobs: The Rise of Polarized and Precarious Employment Systems in the United States, 1970s to 2000s. New York: Russell Sage Foundation.

Kalleberg, A. L. (2018). Precarious Lives: Job Insecurity and Well-Being in Rich Democracies. Cambridge, UK: Polity Press.

Kessler, R. C., Andrews, G., Colpe, L. J., Hiripi, E., Mroczek, D., Normand, S. L. T., Walters, E. E., \& Zaslavsky, A. M. (2002). Short Screening Scales to Monitor Population Prevalence and Trends in Non-Specific Psychological Distress. Psychological Medicine, 32, 959-956.

Newcomb, M. D., Vargas-Carmona, J., \& Galaif, E. R. (1999). Drug Problems and Psychological Distress among a Community Sample of Adults: Predictors, Consequences, or Confound? Journal of Community Psychology, 27, 405-429. https://doi.org/10.1002/(SICI)1520-6629(199907)27:4<405::AID-JCOP4>3.0.CO;2-2

Ornstein, N., Miller, B. F., \& Patel, K. (2020). The Coming Mental-Health Crisis. The Atlantic.

https://www.theatlantic.com/ideas/archive/2020/05/coming-mental-health-crisis/61163 5/

Petterson, S., Westfall, J. M., \& Miller, B. F. (2020). Projected Deaths of Despair during the Coronavirus Recession. Well Being Trust.

https://wellbeingtrust.org/wp-content/uploads/2020/05/WBT_Deaths-of-Despair_CO VID-19-FINAL-FINAL.pdf

Pilkington, E., \& Rao, A. (2020, April 10). A Tale of Two New Yorks: Pandemic Lays Bare a City's Shocking Inequities. The Guardian.

https://www.theguardian.com/us-news/2020/apr/10/new-york-coronavirus-inequalitydivide-two-cities

Presser, H. B. (2003). Working in a 24/7 Economy: Challenges for American families. New York: Russell Sage Foundation.

Schuckit, M. A. (1986). Genetic and Clinical Implications of Alcoholism and Affective Disorder. American Journal of Psychiatry, 143, 140-147. https://doi.org/10.1176/ajp.143.2.140

Vives, A., Amable, M., Ferrer, M., Moncada, S., Llorens, C., Muntaner, C., Benavides, F. G., \& Benach, J. (2010). The Employment Precariousness Scale (EPRES): Psychometric Properties of a New Tool for Epidemiological Studies among Waged and Salaried Workers. Occupational and Environmental Medicine, 67, 548-555.

https://doi.org/10.1136/oem.2009.048967

Vives, A., Gonzáleza, F., Moncadae, S., Llorense, C., \& Benach, J. (2015). Measuring Precarious Employment in Times of Crisis: The Revised Employment Precariousness Scale (EPRES) in Spain. Gaceta Sanitaria, 29, 379-382.

https://doi.org/10.1016/j.gaceta.2015.06.008

Wan, W., \& Long, H. (2020). “Cries for Help”: Drug Overdoses Are Soaring during the Coronavirus Pandemic. The Washington Post. https://www.washingtonpost.com/health/2020/07/01/coronavirus-drug-overdose/

Wiesner, M., Windle, M., \& Freeman, A. (2005). Work Stress, Substance Use, and Depression among Young Adult Workers: An Examination of Main and Moderator Effect Model. Journal of Occupational Health Psychology, 10, 83-96.

https://doi.org/10.1037/1076-8998.10.2.83 